\title{
Ascites-derived IL-6 and IL-10 synergistically expand CD14+HLA-DR-/low myeloid-derived suppressor cells in ovarian cancer patients
}

\author{
Liangliang Wu ${ }^{1, *}$, Zhaoyang Deng ${ }^{2, *}$, Yaojun Peng ${ }^{1}$, Lu Han ${ }^{3}$, Jing Liu ${ }^{1}$, Linxiong \\ Wang ${ }^{1}$, Bohua $\mathrm{Li}^{4}$, Jian Zhao ${ }^{4}$, Shunchang $\mathrm{Jiao}^{1,3}$ and Huafeng $\mathrm{Wei}^{1}$ \\ ${ }^{1}$ Key Lab of Cancer Center, General Hospital of Chinese PLA \& Beijing Key Laboratory of Cell Engineering \& Antibody, Beijing, \\ China \\ ${ }^{2}$ Surgical Division, General Hospital of Chinese PLA, Beijing, China \\ ${ }^{3}$ Department of Internal Oncology, General Hospital of Chinese PLA, Beijing, China \\ ${ }^{4}$ Shanghai Key Laboratory for Molecular Imaging, Shanghai University of Medicine \& Health Sciences \\ *These authors have contributed equally to the work \\ Correspondence to: Huafeng Wei, email: foxp3_smmu@163.com
}

Shunchang Jiao, email: jiaosc@me.com

Keywords: MDSC, ovarian cancer, IL-6, IL-10, STAT3

Received: March 13,2017 Accepted: June 27, $2017 \quad$ Published: August 10, 2017

Copyright: Wu et al. This is an open-access article distributed under the terms of the Creative Commons Attribution License 3.0 (CC BY 3.0), which permits unrestricted use, distribution, and reproduction in any medium, provided the original author and source are credited.

\section{ABSTRACT}

Myeloid-derived suppressor cells (MDSC) play a key immunosuppressive role in various types of cancer, including ovarian cancer (OC). In this study, we characterized CD14 ${ }^{+}$HLA-DR $^{-/ 10}$ MDSC with a typical monocytic phenotype (M-MDSC) in the peripheral blood (PB) and ascites from OC patients. Compared to healthy donors, OC patients had a significantly increased abundance of M-MDSC in both PB and ascites; importantly, their abundance in both compartments was inversely associated with the prognosis where OC patients with higher level of M-MDSC having a shorter relapse-free survival. Intriguingly, we demonstrated that M-MDSC could be readily induced by ascitic fluids (AF) from OC patients, which was predominantly dependent on IL-6, IL-10 and STAT3 activation as neutralization of IL-6 and/or IL-10 or inhibition of STAT3 abrogated MDSC's expansion while recombinant IL-6 and IL-10 recapitulated the expansive effect of AF; furthermore, predominantly elevated levels of IL-6 and IL-10 has been noted in the AF which was positively correlated with the abundance of M-MDSC as well as poor prognosis of OC patients. As expected, we observed that AF-driven STAT3 activation upregulated the expression of arginase (ARG1) and inducible nitric oxide synthase (iNOS) in induced M-MDSC through which these MDSC executed the immunosuppressive activity. Taken together, these results demonstrate that abundant M-MDSC are present in both periphery and ascites of $O C$ patients whose accumulation and suppressive activity is critically attributable to ascites-derived IL-6 and IL-10 and their downstream STAT3 signal, thus providing a potentially novel therapeutic option by locally targeting MDSC to improve antitumor efficacy.

\section{INTRODUCTION}

$\mathrm{OC}(\mathrm{OC})$ is the most deadly gynecologic malignancy with over $70 \%$ of patients having advanced disease at the time of diagnosis. Surgical debulking in combination with platinum-based adjuvant chemotherapy remains first-line therapy to which about $80 \%$ of patients will initially respond well; however, most of these patients eventually succumb to their disease due to the outgrowth and spreading of chemoresistant cancer cells to serous membranes throughout 
the peritoneal cavity $[1,2]$. During this metastatic process, malignant ascites is formed by a malignant effusion building up in the peritoneal cavity at advanced cancer stages, as a carrier, greatly facilitates the passive dissemination of cells shed from the primary tumor cells, and is therefore an essential determinant of metastatic dissemination [3, 4]. This malignant ascites is rich in tumor-promoting soluble factors, cancer cells and immune cells; though its role in fostering OC metastasis has been subject of intensive investigation, the contribution of its host-derived cellular constituents remains poorly understood $[2,5]$.

Accumulating evidence demonstrates that accumulation of pathologically activated immature myeloidderived suppressor cells (MDSC) with potent immunesuppressive activity is one of the major immunological hallmarks of cancer progression and metastasis [6]. MDSC represent a heterogeneous population of immature myeloid cells at different stages of differentiation, including immature precursors of macrophages, granulocytes, and dendritic cells (DC) [7, 8]. In mice, MDSC were historically defined as cells expressing both Gr-1 and CD11b markers [9]. It is now established that MDSC consist of two major groups of cells with mononuclear MDSCs (M-MDSC) and polymorphonuclear MDSCs (PMN-MDSC) defined as $\mathrm{CD} 11 \mathrm{~b}^{+} \mathrm{Ly} 6 \mathrm{C}^{\text {high }} \mathrm{Ly}_{6 \mathrm{G}}{ }^{-}$cells and $\mathrm{CD} 11 \mathrm{~b}^{+} \mathrm{Ly} 6 \mathrm{C}^{\text {low }} \mathrm{Ly}_{6} \mathrm{G}^{+}$ cells respectively [9]; accordingly, human equivalent to M-MDSC were defined as $\mathrm{CD} 33^{+} \mathrm{CD} 14^{+} \mathrm{HLA}-\mathrm{DR}^{-1}$ ${ }^{\text {low }} \mathrm{CD} 15^{-}$cells and PMN-MDSCs as $\mathrm{CD} 33^{+} \mathrm{CD} 14^{-} \mathrm{CD} 15^{+}$ or $\mathrm{CD}^{2} 3^{+} \mathrm{CD} 14^{-} \mathrm{CD} 66 \mathrm{~b}^{+}$cells [10]. As an important player contributing to the immunosuppressive tumor microenvironment, MDSC's abundance was frequently reported to be markedly increased in the peripheral blood (PB) and tumor tissues from cancer patients and correlated with metastatic tumor burden, clinical stage and/or prognosis of cancer patients in many cancer types [7, 8, 11], including OC $[12,13]$. Regarding OC, research group led by Freedman previously identified a subpopulation of IL10-producing CD14 ${ }^{+} \mathrm{HLA}-\mathrm{DR}^{-}$monocytes with suppressive activity against T-cell effector function and proliferation in malignant ascites from $\mathrm{OC}$ patients which presented the features of M-MDSC described currently [14]; furthermore, Natasa et al. reported the presence of CD $11 \mathrm{~b}^{+} \mathrm{CD} 14^{+} \mathrm{CD} 33^{+}$ MDSC in OC patients which was attractive into ascites by PEG2-controlled CXCL12/CXCR4 chemotactic axis [12]; recently, Cui et al. demonstrated the inverse relationship between intratumoral $\mathrm{CD} 45^{-} \mathrm{CD} 33^{+}$MDSC content and overall survival of patients with OC [13], indicating the clinical relevance of MDSC in OC. In spite of these pioneering studies, detailed characterization of MDSC phenotype, function, and generation in the $\mathrm{PB}$ and/or ascites from OC patients remains to be needed.

In our study, we have defined the frequency, phenotype, generation and function of $\mathrm{CD} 14^{+} \mathrm{HLA}-\mathrm{DR}^{-}$ ${ }^{10} \mathrm{MDSC}$ in the $\mathrm{PB}$ and ascites isolated from OC patients. We show that these MDSC are abundantly enriched in the $\mathrm{PB}$ and in particular, in the ascites; they express the surface markers typical of M-MDSC, and are able to suppress autologous T-cell proliferation and effector cytokine production; more importantly, their abundance in both $\mathrm{PB}$ and ascites is inversely correlated with the prognosis of OC patients; We further demonstrate that these MDSC can be induced by ascitic fluids (AF) where high levels of IL-6 and IL-10 play an essential role via activation of downstream STAT3 signaling pathway. We further show that induced CD14 ${ }^{+} \mathrm{HLA}^{-D R^{-10}} \mathrm{MDSC}^{-}$execute the immunosuppressive function via ARG1 and iNOS upregulated by AF-driven STAT3 activation.

\section{RESULTS}

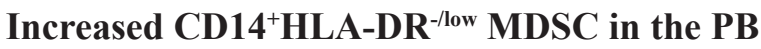 and ascites from $\mathrm{OC}$ patients}

We determined the frequency of CD14 HLA$\mathrm{DR}^{- \text {llow }}$ cells in the $\mathrm{PB}$ of $\mathrm{OC}$ patients before treatment and found that there was a larger accumulation of these potentially suppressive cells in OC patients compared to healthy donors. Though mean $\mathrm{CD} 14^{+}$monocytes in the PB leukocytes show no difference (Supplementargy Figure 1A), mean CD14 $4^{+}$LA-DR ${ }^{- \text {low }}$ cells in total $\mathrm{CD}^{2} 3^{+}$myeloid cells in OC patients was $18.7 \% \pm 8.3 \%$ in comparison with $5.5 \% \pm 5.3 \%$ in healthy donors (Figure 1A). Consistent with previous studies, we observed that the abundance of $\mathrm{CD} 14^{+} \mathrm{HLA}-\mathrm{DR}^{- \text {low }}$ cells was correlated with the cancer stage where a significant increase was seen in the

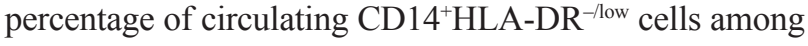
advanced stage (stage III/IV) OC patients $(21.5 \% \pm 8.3 \%)$ as compared with early stage (stage I/II) OC patients $(12.9 \% \pm 4.3 \%)$ (Figure 1B). No correlation was noted between the percentage of circulating CD14 ${ }^{+} \mathrm{HLA}-\mathrm{DR}^{- \text {llow }}$ cells and tumor grade or cancer subtype (Supplementary Figure $1 \mathrm{~B}$ and $1 \mathrm{C}$ ). When we analyzed CD14 ${ }^{+} \mathrm{HLA}^{-D R^{- \text {low }}}$ cells in the accompanying ascites, we noted the significantly higher percentage of these cells in the ascites $(46.6 \% \pm$ $17.9 \%)$ as compared to that in the $\mathrm{PB}(21.5 \% \pm 8.3 \%)$ and also an increase in the percentage of $\mathrm{CD} 14^{+}$monocytes (Supplementary Figure 1D). The representative dotplots for CD $14^{+} \mathrm{HLA}^{-D R^{- \text {low }}}$ cells were shown in Figure 1D.

Further phenotypic analysis of surface markers showed that $\mathrm{CD} 14^{+} \mathrm{HLA}-\mathrm{DR}^{- \text {llow }}$ cells represented the features of M-MDSC; these cells from both $\mathrm{PB}$ and ascites expressed the myeloid markers CD11b, CD13, and CD39 as well as CD124, a marker of M-MDSC previously

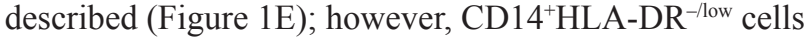
from these two compartment exhibited both similarity and distinction in the expression of cosignaling (costimulatory and coinhibitory) molecules in that both had the low levels of CD80 and PD-L1 expression, but intermediate levels of CD86 or CD83 expression on circulating or ascitic cells respectively. Distinguishable from tumorassociated macrophages (TAM), we did not see expression 

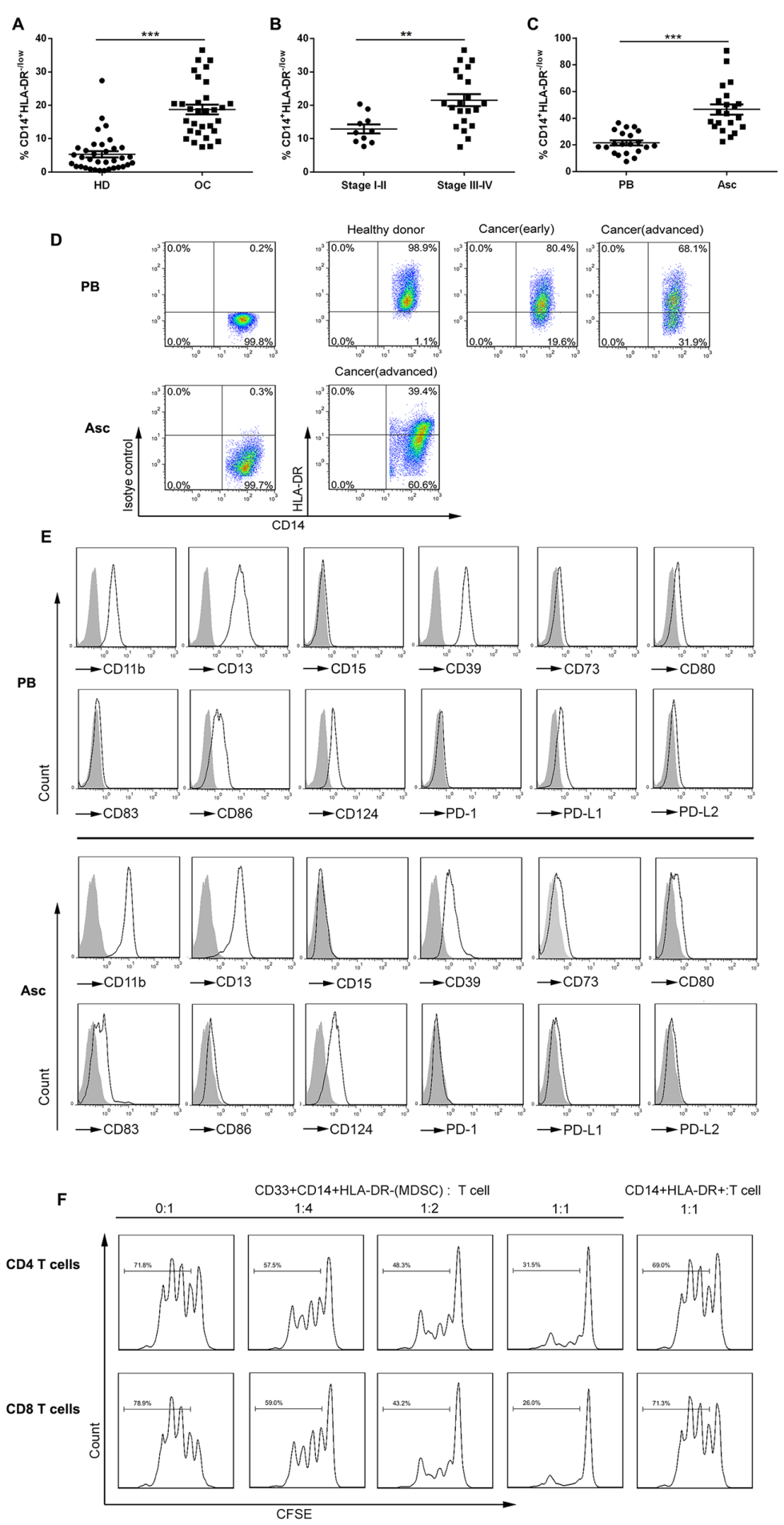

Figure 1: The distribution, phenotypes and suppressive function of $\mathrm{CD}^{+} 4^{+} \mathrm{HLA}-\mathrm{DR} \mathrm{R}^{-10} \mathrm{MDSC}$ in the PB and ascites from OC patients. (A) Relative abundance of circulating CD14 $4^{+} \mathrm{HL}_{-} \mathrm{DR}^{-1 / 0} \mathrm{MDSC}$ (with respect to $\mathrm{CD} 33^{+}$cells) in OC patients (n $=31$ ) versus healthy donors $(\mathrm{HD} ; \mathrm{n}=35)$. The mean $\mathrm{CD} 33^{+}$cells from these populations were not statistically different. (B) Relative

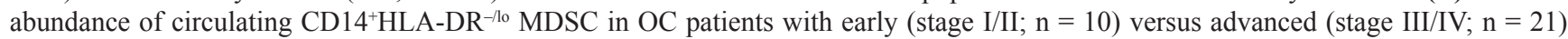
disease. (C) Relative abundance of CD14 ${ }^{+} \mathrm{HLA}_{-} \mathrm{DR}^{-1 \mathrm{lo}} \mathrm{MDSC}$ in the PB versus accompanying ascites from the same OC patients $(\mathrm{n}=$ 21). (D) Representative dotplots of CD14 $4^{+} \mathrm{HLA}_{-}-\mathrm{RR}^{-1 / 0} \mathrm{MDSC}$ in the PB and/or accompanying ascites from HD or OC patients with early or advanced disease. (E) Representative histograms of MDSC surface markers on CD14 $4^{+} \mathrm{HLA}^{-\mathrm{DR}^{-1 /}}$ MDSC in the PB or accompanying

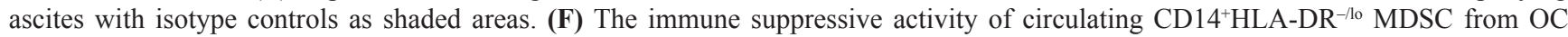
patients on autologous $\mathrm{T}$ cell proliferation at the varying $\mathrm{T}$ cell/MDSC ratios with CD14 $\mathrm{HLA}-\mathrm{DR}^{+}$cells from the same donors as control. ${ }^{* *} \mathrm{p}<0.01,{ }^{* * *} \mathrm{p}<0.001$, unpaired student $t$ test for A and B or paired student $t$ test for $\mathrm{C}$. 
of CD68, CD204 and CD206 expression on these cells (Supplementary Figure 1E).

We next evaluated the immunosuppressive activity of these cells by $\mathrm{T}$ cell/MDSC coculture assay. CD14 HLA$\mathrm{DR}^{- \text {llow }}$ cells as well as control $\mathrm{CD} 14^{+} \mathrm{HLA}_{-}-\mathrm{DR}^{+}$cells were freshly isolated from the $\mathrm{PB}$ of $\mathrm{OC}$ patients by flow cytometry using the gating strategy described in Supplementary Figure $1 \mathrm{~F}$ and then were cocultured with CFSE-labeled autologous $\mathrm{CD}^{+}$and $\mathrm{CD}^{+} \mathrm{T}$ cells at the varying ratios; as shown in Figure $1 \mathrm{~F}, \mathrm{CD} 14^{+} \mathrm{HLA}^{-\mathrm{DR}^{-/ \text {low }}}$ cells were found to suppress autologous $\mathrm{CD}^{+}$and $\mathrm{CD} 8^{+}$ $\mathrm{T}$ cell proliferation in vitro at even 4:1 T cell/MDSC ratio while $\mathrm{CD} 14^{+} \mathrm{HLA}-\mathrm{DR}^{+}$cells from the same patients did not, validating the identity of MDSC for $\mathrm{CD}^{1} 4^{+} \mathrm{HLA}_{-\mathrm{DR}}^{-/ \text {low }}$ cells from $\mathrm{OC}$ at the functional level. Sorted CD14 ${ }^{+} \mathrm{HLA}-$ $\mathrm{DR}^{-/ \text {low }}$ cells sorted from the accompanying ascites of OC patients exhibited a similar immunosuppressive activity on autologous T cells in coculture assays (data not shown).

\section{Significantly elevated levels of IL-6 and IL-10 are associated with the abundance of CD14 $^{+}$HLA-DR- $^{- \text {low }}$ MDSC in the AF}

The data described above demonstrated a predominant increased $\mathrm{CD}_{14}^{+} \mathrm{HLA}^{-\mathrm{DR}^{-/ \text {low }}}$ cells in the accompanying ascites in comparison with the PB of OC patients; as previous studies have shown the presence of multiple inflammatory cytokines in the AF from $\mathrm{OC}$ patients and several inflammatory cytokines have been defined to be able to promote the expansion and accumulation of MDSC, we examined the levels of multiple inflammatory cytokines in the paired $\mathrm{PB}$ sera and $\mathrm{AF}$ from $\mathrm{OC}$ patients by cytokine array and then determined whether their levels were associated with the abundance of CD14 ${ }^{+} \mathrm{HLA}_{-} \mathrm{DR}^{- \text {llow }}$ MDSC. Cytokine analysis demonstrated a marked elevation of IL- 6 and IL-10 in the AF from OC patients as compared to the accompany sera as well as sera from healthy donor (Figure 2A and 2B); no difference in the levels of other 10 cytokines (IL-1 $\beta$, IL-2, IL-4, IL-5, IL-9, IL-22, IL13, IL-17A, IFN- $\gamma$, TNF- $\alpha$ ) were noted (Supplementary Figure 2). Further correlation analysis confirmed a significant correlation of CD14 ${ }^{+} \mathrm{HLA}_{-}-\mathrm{DR}^{-/ \text {low }} \mathrm{MDSC}$ with the concentration of both IL- $6(\mathrm{p}=0.0021$; correlation coefficient $r=0.669$; Figure 2C) and IL-10 ( $p=0.0005$; correlation coefficient $r=0.7566$; Figure 2D). None of the other cytokines tested was significantly associated with the abundance of CD $14^{+} \mathrm{HLA}_{-\mathrm{DR}}{ }^{- \text {low }}$ MDSC (Supplementary Table 3 ). We also observed significant correlation between IL-6 and IL-10 ( $\mathrm{p}=0.001)$ while other correlations were not detectable (Supplementary Table 4 ).

\section{Association of relapse-free survival with the levels of CD14 ${ }^{+}$HLA-DR $^{-l l o w}$ MDSC, IL-6 and IL-10}

We further analyzed potential correlations between the abundance of CD $14^{+} \mathrm{HLA}_{-} \mathrm{DR}^{-/ \text {low }} \mathrm{MDSC}$ in the PB and ascites or levels of IL- 6 and IL-10 in the AF and clinical progression of OC patients. All patients with a postsurgery period of at least 6 months (range 7-18 months) were included in our study $(n=21$ for $\mathrm{PB}$ and $\mathrm{n}=$ 11 for ascites). For each parameter, patients were grouped as "high" or "low" using the respective median as a cutoff point. These datasets were analyzed for association with relapse-free survival (RFS). As expected, the frequency of CD14 ${ }^{+} \mathrm{HLA}_{-\mathrm{DR}}{ }^{-/ \text {low }}$ MDSC in both PB and ascites was inversely associated with RFS (log-rank test, $\mathrm{p}=0.0215$ and 0.0226; Figure 3A and Figure 3B); furthermore, we also found an inverse correlation between RFS and the levels of IL-6 and IL-10 in the AF (log-rank test, p = 0.0162 and 0.0175; Figure 3C and Figure 3D). A similar negative association was also observed between RFS and tumor stage, but not histological grading (data not shown).

\section{Functional CD14 ${ }^{+}$HLA-DR $^{-/ l o w}$ MDSC can be significantly expanded by the AF from OC patients}

To define the origin of markedly increased CD14 ${ }^{+} \mathrm{HLA}_{-}-\mathrm{DR}^{-/ \mathrm{low}} \mathrm{MDSC}$ in the ascites as compared to the $\mathrm{PB}$ from $\mathrm{OC}$ patients, we cultivated the freshly isolated PBMC from healthy donors in the presence of varying concentrations of AF from OC patients for up to 72 hours and then analyzed the abundance of CD14 HLA$\mathrm{DR}^{- \text {llow }}$ MDSC by flow cytometry; as shown in Figure 4A, addition of AF from OC patients significantly potentiated the expansion of $\mathrm{CD} 14^{+} \mathrm{HLA}_{-} \mathrm{DR}^{-/ \text {low }}$ cells in a dosedependent manner within 72 hours with 48 hours being the optimal time. The representative dotplots for MDSC expansion were also shown in Figure 4A.

We next examined the functionality of AF-expanded CD14 ${ }^{+}$HLA-DR ${ }^{- \text {low }}$ cells by $\mathrm{T}$ cell/MDSC coculture assay; as shown in Figure 4B, AF-expanded CD14 ${ }^{+} \mathrm{HLA}_{-}-\mathrm{DR}^{-/ \text {low }}$ cells were found to suppress the proliferation of autologous $\mathrm{CD}^{+}$and $\mathrm{CD}^{+} \mathrm{T}$ cells in vitro as similar to that of freshly isolated circulating $\mathrm{CD} 14^{+} \mathrm{HLA}_{-} \mathrm{DR}^{-/ \mathrm{low}} \mathrm{MDSC}$; moreover, they were also able to inhibit the production of effector cytokine IL-2 and IFN- $\gamma$ of autologous $\mathrm{CD}^{+}$and $\mathrm{CD}^{+} \mathrm{T}$ cells (Figure 4C), confirming the identity of MDSC for AFexpanded CD14 ${ }^{+} \mathrm{HLA}-\mathrm{DR}^{-/ \text {low }}$ cells at the functional levels.

\section{Both IL-6 and IL-10 critically contributed to AF-driven expansion of CD14 ${ }^{+} \mathrm{HLA}^{-D R^{-/ l o w}}$ MDSC in a STAT3-dependent manner}

Given the data above showing the presence of high levels of IL- 6 and IL-10 and their levels correlating with the abundance of CD $14^{+} \mathrm{HLA}_{-} \mathrm{DR}^{-/ \text {low }} \mathrm{MDSC}$ in ascites from OC patients, we next defined whether AF-driven expansion of $\mathrm{CD} 14^{+} \mathrm{HLA}-\mathrm{DR}^{-/ \text {low }} \mathrm{MDSC}$ was due to the presence of IL-6 and/or IL-10 in the ascites from OC patients. To this end, we cultivated the PBMC freshly isolated from healthy donors with the AF from $\mathrm{OC}$ 
patients in the presence of neutralizing antibodies against IL-6 and/or IL-10 for 48 hours and then determined the frequency of CD14 $4^{+} \mathrm{HA}_{-}-\mathrm{DR}^{-/ \text {low }} \mathrm{MDSC}$ by flow cytometry; as shown in Figure 5A, addition of either IL-6 or IL-10 neutralizing antibodies alone significantly attenuated the expansion of AF-driven CD14 ${ }^{+} \mathrm{HLA}_{-} \mathrm{DR}^{-}$ low MDSC with IL-6-specific neutralizing antibodies having a greater effect; furthermore, concomitant addition of both IL-6 and IL-10 neutralizing antibodies almost completely abrogated the expansive effect of AF on $\mathrm{CD} 14^{+} \mathrm{HLA}-\mathrm{DR}^{-/ \text {low }} \mathrm{MDSC}$, indicating that the high levels of IL-6 and IL-10 in the ascites from OC patients were indispensable for the AF-driven expansion of CD14+HLA-DR ${ }^{-1 \text { low }}$ MDSC.
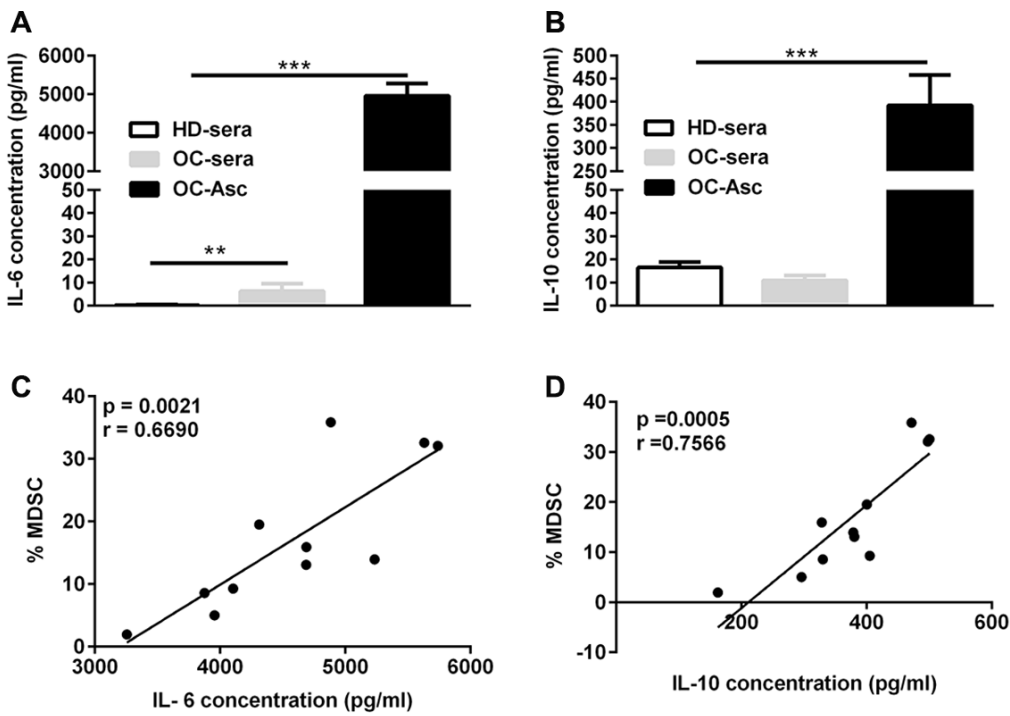

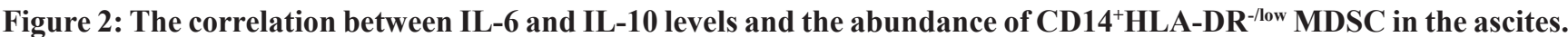
(A) IL-6 concentration in the sera and/or accompanying ascites from $\mathrm{HD}(\mathrm{n}=21)$ or OC $(\mathrm{n}=11)$ patients. (B) IL-10 concentration in the sera and/or accompanying ascites from HD or OC patients. (C) The correlation between the abundance of CD14 ${ }^{+} \mathrm{HLA}^{-D R^{-1 / 0}} \mathrm{MDSC}^{\mathrm{and}}$

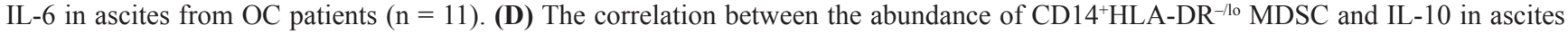
from OC patients $(\mathrm{n}=11) .{ }^{* *} \mathrm{p}<0.001$, one-way ANOVA followed by Tukey's multiple comparisons test for A and B or Pearson test for $\mathrm{C}$ and $\mathrm{D}$.
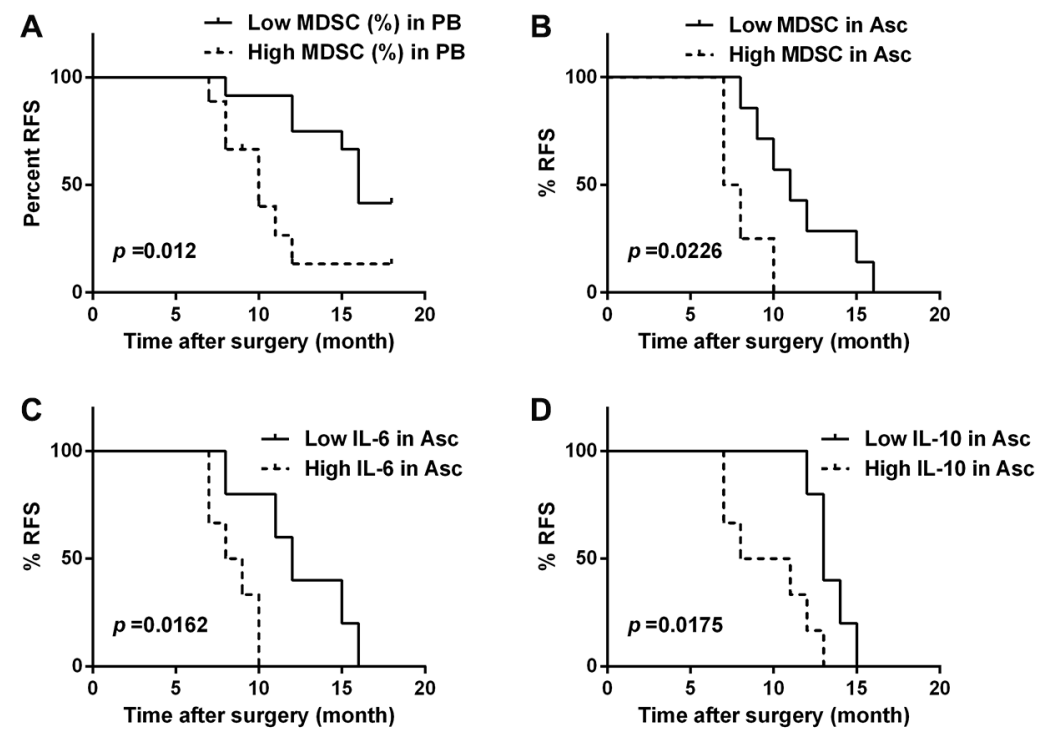

Figure 3: The correlation between relapse-free survival (RFS) and the abundance of $\mathrm{CD}_{14}^{+}{ }^{+} \mathrm{HLA}_{-D R^{-/ l o w}} \mathrm{MDSC}^{-}$and the levels of IL-6 and IL-10 in the OC patients. (A) Kaplan-Meier plots showing the correlation between RFS and high or low levels (median as cutoff) of CD14 ${ }^{+} \mathrm{HLA}_{-} \mathrm{DR}^{-/ 10} \mathrm{MDSC}$ in the PB (A) or accompanying ascites (B), and IL-6 (C) or IL-10 (D) concentration in the accompanying ascites in the OC patients ( $n=21$ for PB and $n=11$ for ascites) with $p$-Values determined by Mantel-Cox log-rank test. 
As IL-6 and IL-10 engagement on their receptors leads to the activation of downstream STAT3 signaling pathway, we applied the Stattic, a small-molecule STAT3 inhibitor, to further define the role of IL- 6 and IL-10 and their downstream signal in expansion of CD14 $4^{+} \mathrm{HLA}-$ $\mathrm{DR}^{-/ \text {low }}$ MDSC. We confirmed that addition of AF from OC patients into PBMC from healthy donors induced a rapid and durative activation of STAT3 signaling pathway where inclusion of Stattic as well as IL-6 and
IL-10 neutralizing antibodies blocked STAT3 activation (Supplementary Figure 3). As expected, inhibition of STAT3 activation by Stattic abrogated the expansion of AF-driven CD14 ${ }^{+} \mathrm{HLA}_{-} \mathrm{DR}^{-/ \text {low }}$ MDSC similar to that done by neutralizing antibodies against IL- 6 and IL-10 (Figure $5 \mathrm{~B})$, validating the critical role of both IL-6/IL-10 and their triggered downstream STAT3 signal in contributing to AF-driven expansion of $\mathrm{CD} 14^{+} \mathrm{HLA}^{-\mathrm{DR}^{-/ \text {low }}}$ MDSC.
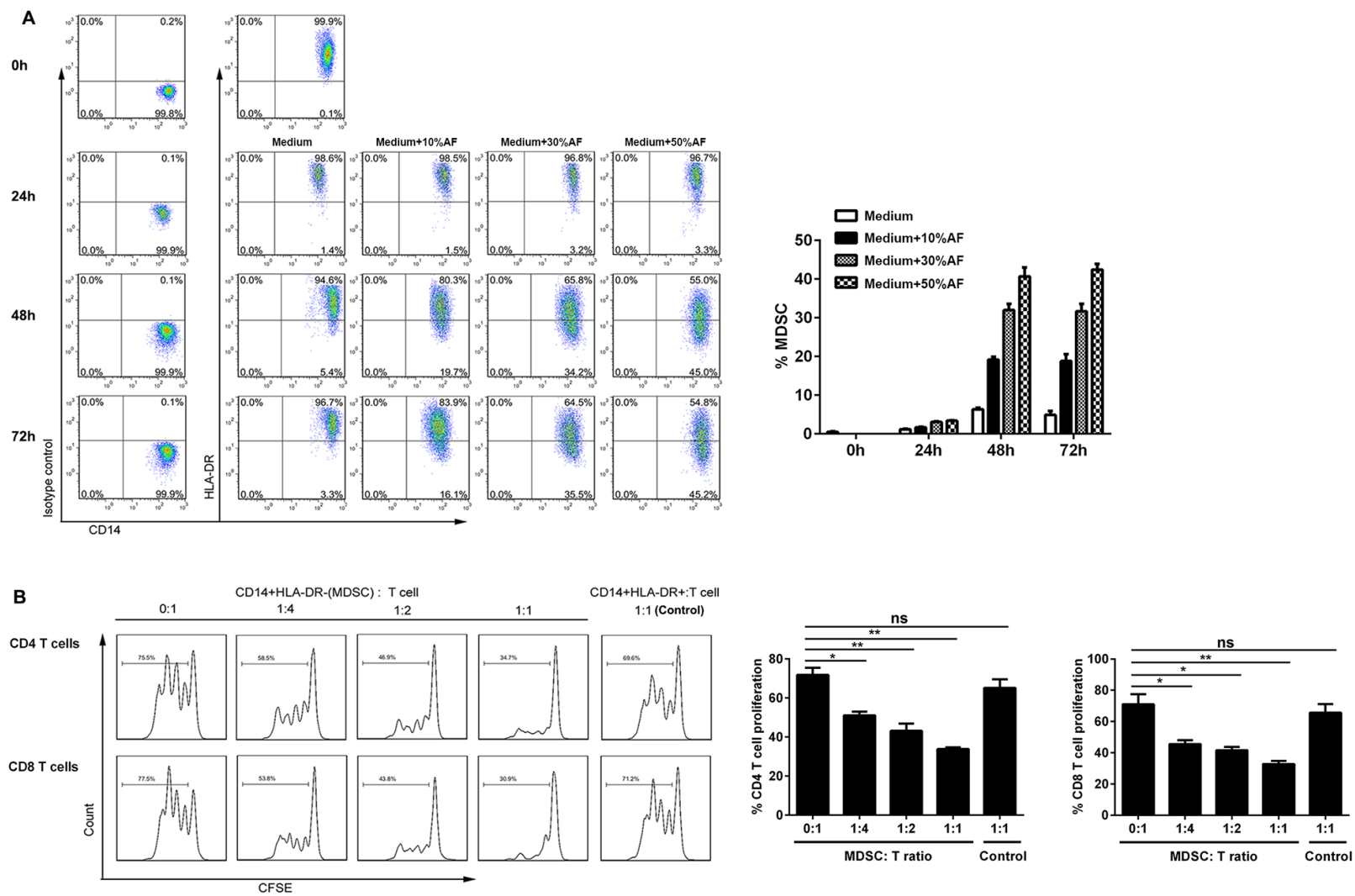

C
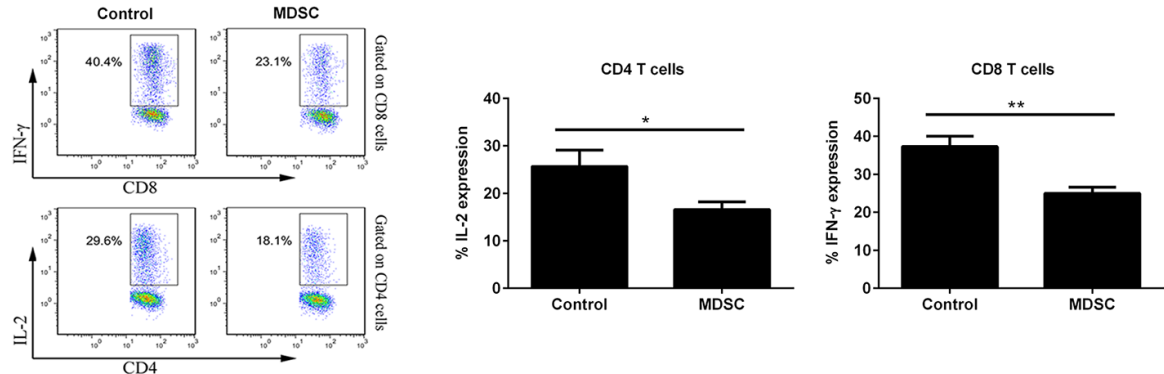

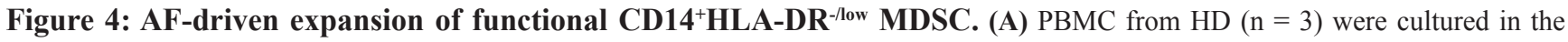
presence of varying concentrations $(10,30,50 \% \mathrm{v} / \mathrm{v})$ of AF from OC patients $(\mathrm{n}=4)$ for up to 72 hours and then analyzed for the abundance of $\mathrm{CD} 14^{+} \mathrm{HLA}_{-\mathrm{DR}}^{-/ \text {low }} \mathrm{MDSC}$ by flow cytometry. The representative dotplots were shown in left panel and the statistics were shown in right graph. (B) Both $\mathrm{CD} 14^{+} \mathrm{HLA}_{-\mathrm{DR}}^{-/ \mathrm{lo}} \mathrm{MDSC}$ and CD14 ${ }^{+} \mathrm{HLA}-\mathrm{DR}^{+}$control cells from AF-treated PBMC (30\% v/v, 48 hours) were sorted by flow cytometry and then assayed immune suppressive activity on autologous $\mathrm{T}$ cell proliferation at the varying $\mathrm{T}$ cell/MDSC ratios. The representative dotplots were shown in left panel and the statistics were shown in right graph. (C) CD14 $4^{+}$AL-DR ${ }^{-1 / 0}$ MDSC were also assayed immune suppressive activity by evaluating IL-2 and IFN- $\gamma$ production in autologous $\mathrm{CD} 4^{+}$and $\mathrm{CD} 8^{+} \mathrm{T}$ cells by intracellular staining. The data are expressed as mean \pm SEM of 4 biological replicates and representative of three independent experiments. *p $<0.05$, ${ }^{* *} \mathrm{p}<0.01$, paired student $t$ test for B or one-way ANOVA followed by Tukey's multiple comparisons test for C. 
To directly confirm the role of IL-6 and IL-10 in expansion of $\mathrm{CD}_{14}{ }^{+} \mathrm{HLA}-\mathrm{DR}^{-/ \text {low }} \mathrm{MDSC}$, we treated PBMC from healthy donors with recombinant human IL-6 $(5 \mathrm{ng} / \mathrm{ml})$ and IL-10 $(0.5 \mathrm{ng} / \mathrm{ml})$ at the concentrations similar to that found in the ascites from OC patients for 48 hours. As shown in Supplementary Figure 4, combined
IL-6 and IL-10 treatment induced a significant expansion of $\mathrm{CD} 14^{+} \mathrm{HLA}-\mathrm{DR}{ }^{-/ \text {low }}$ MDSC which was dependent on STAT3 activation since STAT3 inhibitor Stattic abrogated this expansion; however, the extent of CD14 ${ }^{+} \mathrm{HLA}_{-} \mathrm{DR}^{-}$ low MDSC expansion induced by combined IL-6 and IL-10 did not reach the level achieved by the AF from
A

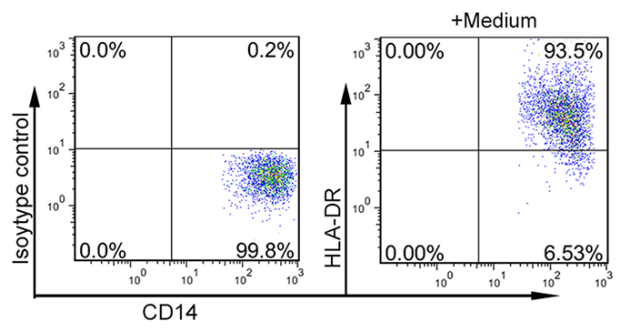

Anti-IL-6 $2 \mu \mathrm{g} / \mathrm{m}$

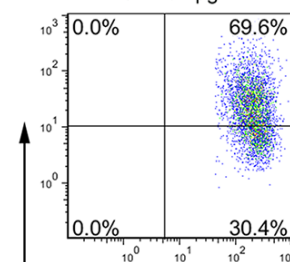

Anti-IL-6 $10 \mu \mathrm{g} / \mathrm{ml}$

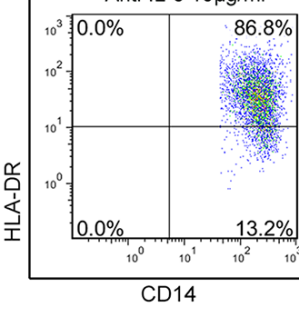

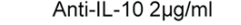

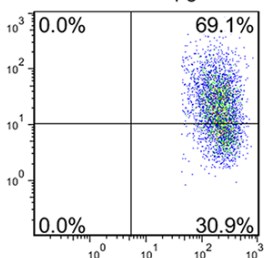

Anti-IL $1010 \mu \mathrm{g} / \mathrm{ml}$

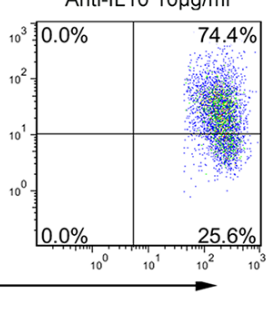

Isotype control $20 \mu \mathrm{g} / \mathrm{ml}$

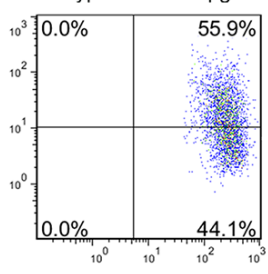

Anti-IL6+anti-IL10 $2 \mu \mathrm{g} / \mathrm{ml}$

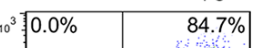

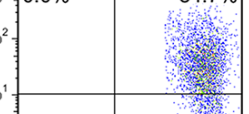

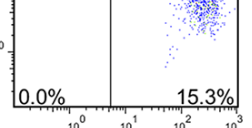

Anti-IL6+anti-IL10 10 $\mu \mathrm{g} / \mathrm{m}$ |
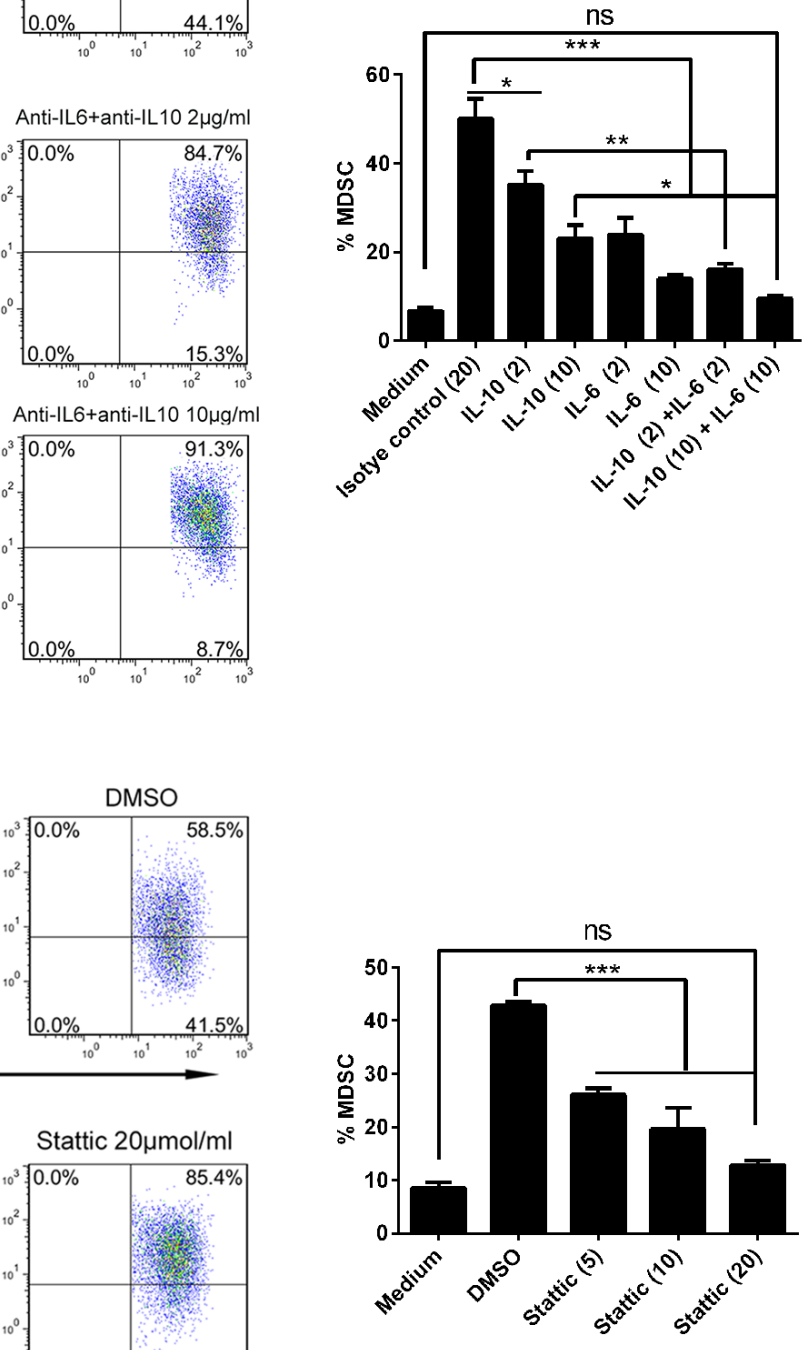

B

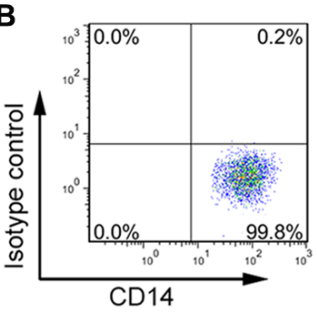

Stattic $5 \mu \mathrm{mol} / \mathrm{ml}$

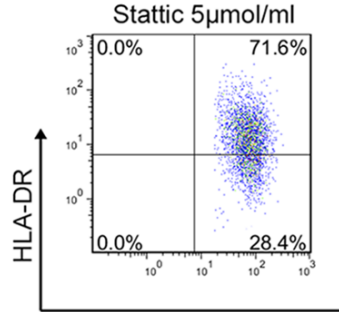

CD14
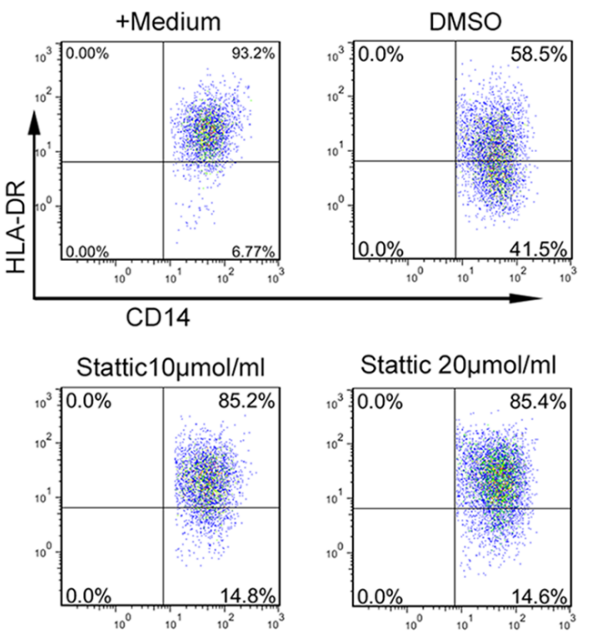

Stattic $20 \mu \mathrm{mol} / \mathrm{ml}$

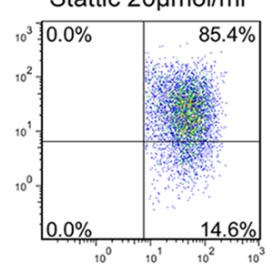

Figure 5: AF-driven expansion of CD14 HLA-DR ${ }^{-/ 10 w}$ MDSC was dependent on IL-6/IL10-STAT3 signal pathway. PBMC from HD $(n=3)$ were treated with the AF $(50 \% \mathrm{v} / \mathrm{v})$ from OC patients $(n=4)$ in the presence of neutralizing antibodies against IL-6 and/or IL-10 (A) or STAT3 inhibitor stattic (B) for 48 hours and then analyzed for the abundance of CD14 ${ }^{+}$HLA-DR ${ }^{-/ l o w}$ MDSC by flow cytometry. Addition of isotype antibody or DMSO was as controls. The representative dotplots were shown in left panel and the statistics were shown in right graph. The data are expressed as mean \pm SEM of 4 biological replicates and representative of three independent experiments. $* \mathrm{p}<0.05, * * * \mathrm{p}<0.001$, one-way ANOVA followed by Tukey's multiple comparisons test. 
OC patients, indicating that other unidentified mediators existing in the ascites from OC patients may play a role in the production of these MDSC.

\section{AF-induced CD14 ${ }^{+}$HLA-DR ${ }^{-l l o w}$ MDSC executed the immunosuppressive activity via ARG1 and iNOS upregulated by AF-driven STAT3 activation}

To delineate the suppressive mechanisms used by AF-induced CD14 ${ }^{+} \mathrm{HLA}-\mathrm{DR}^{- \text {llow }}$ MDSC, we analyzed the expression of ARG1, iNOS, S100A8 and S100A9, previously well-defined molecules critical for MDSC immunosuppressive function $[7,10]$, in these cells by flow cytometry. As shown in Figure 6A, the AF from ovarian patients predominantly upregulated the expression of ARG1 and iNOS in CD14 ${ }^{+} \mathrm{HLA}_{-} \mathrm{DR}^{\text {-low }}$ MDSC with slight increased expression of S100A8 and S100A9; we further confirmed that both ARG1 and iNOS expression were dependent on the STAT3 activation since STAT3 inhibition by Stattic abrogated their upregulation in AFinduced CD14 ${ }^{+} \mathrm{HLA}-\mathrm{DR}^{- \text {llow }}$ MDSC (Figure 6B).

We next examined whether ARG1 and/or iNOS play a pivotal role in the immunosuppressive activity of AF-induced CD14 ${ }^{+} \mathrm{HLA}-\mathrm{DR}^{- \text {/low }}$ MDSC. To do this, norNOHA and SMT, the small-molecule inhibitor specific for ARG1 and iNOS respectively, were used to determine the involvement of these two candidate molecules. As shown in Figure 6C, AF-induced CD14 ${ }^{+} \mathrm{HLA}^{-\mathrm{DR}^{-1 \text { low }}}$ MDSC suppressed the proliferation of autologous CD4 and $\mathrm{CD} 8^{+} \mathrm{T}$ cells as described above, however, addition of either nor-NOHA or SMT into T cell/MDSC cocultures rescued T-cell proliferation with concomitant inclusion of nor-NOHA and SMT almost completely abrogating the immunosuppressive effect of those MDSC, pointing to the critical role of both ARG1 and iNOS in mediating the immunosuppressive activity of AF-induced $\mathrm{CD} 14^{+} \mathrm{HLA}-$ $\mathrm{DR}^{- \text {llow }}$ MDSC.

\section{DISCUSSION}

In this study, we analyzed the abundance, phenotype, function and/or generation of CD14 $\mathrm{HLA}^{+} \mathrm{DR}^{- \text {llow }} \mathrm{MDSC}$ in the $\mathrm{PB}$ and accompanying ascites from $\mathrm{OC}$ patients. Briefly, increased frequency of CD14 ${ }^{+} \mathrm{HLA}^{-D R^{- \text {low }}}$ MDSC was found in the $\mathrm{PB}$ of $\mathrm{OC}$ patients which is correlated with cancer stage, but not cancer subtype or histological grading; these MDSC express the typical surface markers of M-MDSC and are able to inhibit the autologous T-cell proliferation; we noted a predominant increase of these MDSC in the companying ascites from OC patients which presents a good correlation with the levels of IL-6 and IL10 in those ascites; more importantly, the abundance of these MDSC in both PB and ascites as well as the levels of both IL-6 and IL-10 in the ascites is inversely associated with the RFS of OC patients. Furthermore, the AF from
OC patients is able to readily induce the expansion of CD14 ${ }^{+}$HLA-DR ${ }^{- \text {low }}$ MDSC depending on IL-6/IL-10STAT3 signaling pathway; these AF-induced $\mathrm{CD} 14^{+} \mathrm{HLA}$ $\mathrm{DR}^{- \text {llow }}$ MDSC suppress the T-cell proliferation and effector function by STAT3-controlled ARG1 and iNOS expression.

CD14 HLA-DR ${ }^{- \text {llow }}$ MDSC have been reported to contribute to tumor progression and/or therapy resistance, and increased abundance of these cells has been described in the $\mathrm{PB}$ and/or tumor tissues from hepatocellular carcinoma (HCC), melanoma, lung cancer, head and neck SCC (HNSCC), esophageal SCC and prostate cancer [1523], and in several cancer types, has shown correlation with poor prognosis of cancer patients $[15,20,22]$. Herein, we observed a significantly elevated frequency of CD14 HLA-DR ${ }^{- \text {low }}$ MDSC in both PB and ascites from OC patients with their abundance inversely correlating with RFS, which is consistent with recent finding showing inverse association between intratumoral $\mathrm{CD} 45^{-} \mathrm{CD} 33^{+}$ MDSC content and overall survival of OC patients [13]; these findings altogether indicate that $\mathrm{CD} 33^{+}$MDSC in multiple compartments of $\mathrm{OC}$ patients critically involve in the progression of $\mathrm{OC}$ with the potential of prognostic biomarker.

$\mathrm{CD}^{+} 4^{+} \mathrm{HLA}^{-D R^{-}}{ }^{\text {llow }}$ MDSC from OC patients express the typical surface markers of CD11b, CD33 and CD124. CD124 (IL-4R $\alpha$ ) is a subunit of the IL-4 and IL-13 receptor, both involved in MDSC activation, and has been postulated as a MDSC marker though its functional relevance for MDSC-mediated suppression is yet completely defined [24]. Interestingly, these cells expresses CD39 but not CD73, two ectonucleotidase molecules mediating conversion of immunostimulatory ATP into immunosuppressive adenosine with resulting adenosine acting to suppress Th1, Th2, CTL, and NK cells, among others [25]. A recent study showed that CD39 and CD73 are expressed by mouse MDSC and promote the expansion of and facilitate the suppressive activity of mouse MDSC [26]; therefore, it is possible that $\mathrm{CD} 39$ may play a role in mediating the suppressive activity of CD14 ${ }^{+} \mathrm{HLA}-\mathrm{DR}^{- \text {llow }}$ MDSC on T cells which should be evaluated in our future studies. Consistent with a previous study on melanoma patients [18], we detected variable level of CD80, CD83 and/or CD86 expression on CD14 ${ }^{+} \mathrm{HLA}_{-} \mathrm{DR}^{- \text {llow }}$ MDSC in the PB and/ or ascites from $\mathrm{OC}$; however, their functional significance remains elusive. As these molecules play an important role in stimulating $\mathrm{T}$ cell responses, their expression on CD14 ${ }^{+}$HLA-DR ${ }^{- \text {low }}$ MDSC possibly could enable them to establish antigen-independent contact with $\mathrm{T}$ cells, allowing suppressive factors to act for a longer time and over shorter distances, which still warrant further investigation by using well-designed experiments [18]. Notably, we did not observe the expression of CD68, CD204 and CD206 on CD14 HLA-DR ${ }^{- \text {low }}$ MDSC from OC, making them distinguishable from tumor-associated 
macrophages (TAM) with alternative polarization (M2) which has been well characterized and described to be correlated with RFS of OC patients [27]. As M-MDSC can differentiate into TAM within tumor tissues, it is very likely that same scenario occurs in the ascites and thus not surprising that they have the same clinically relevant prognostic significance [28].

It has been widely accepted that the accumulation of MDSC is driven by tumor-derived inflammatory cytokines and associated signaling pathway, notable IL-6 and its downstream STAT3 signal [7]. Consistent with this concept, we found that the abundance of CD $14^{+} \mathrm{HLA}_{-} \mathrm{DR}^{-/ \text {low }}$ MDSC is positively correlated with IL-6 concentration in the ascites, and incubation of PBMC with the ascites from $\mathrm{OC}$ patients induced the expansion of CD14 ${ }^{+} \mathrm{HLA}_{-} \mathrm{DR}^{-/ \text {low }}$ MDSC depending on IL-6 and their triggered STAT3 signal. As a major mediator of cancerrelated inflammation, IL-6 is mainly derived from both cancer cells and cancer-associated immune cells, and it has been frequently reported to be increased in the sera, ascites and/or tumor tissue from OC patients correlating with the infiltration of myeloid cells and poor prognosis [29-32]. The underlying mechanisms by which IL-6 promotes the carcinogenesis and progression of $\mathrm{OC}$ are extremely complex and multifactorial [33]; our findings that IL-6 along with IL-10 and possibly other mediators promotes the expansion of $\mathrm{CD} 14^{+} \mathrm{HLA}^{-D R^{-/ \text {low }}} \mathrm{MDSC}$ provides an explanation for the increased presence of these immunosuppressive cells in the ascites and possible tumor tissues from $\mathrm{OC}$ patients thus adding another layer to the complex roles of IL-6. Our results are consistent with a recent study of esophageal squamous cell carcinoma (SCC) where IL-6 induced the accumulation of $\mathrm{CD} 11 \mathrm{~b}^{+} \mathrm{CD} 14^{+} \mathrm{HLA}-\mathrm{DR}{ }^{-}$MDSC by stimulating STAT3 signal and its level in plasma samples was correlated with tumor progression and poor prognosis [17]. Thus, targeting IL-6 would be a viable strategy to decrease/ deplete the level of MDSC in cancer patients to promote
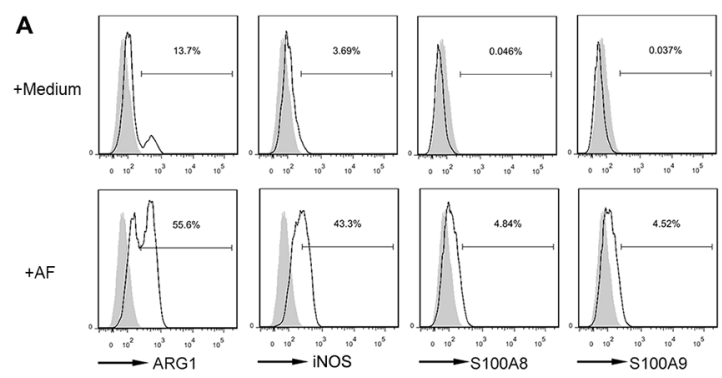

B
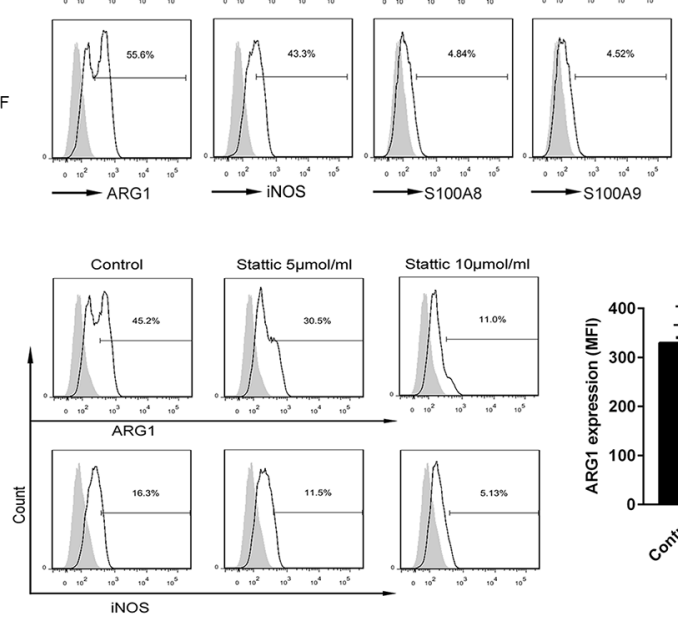

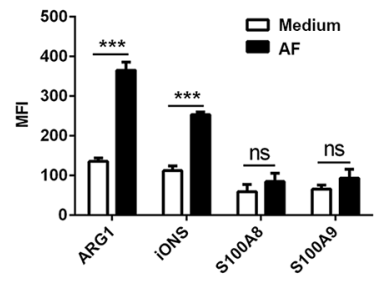

C
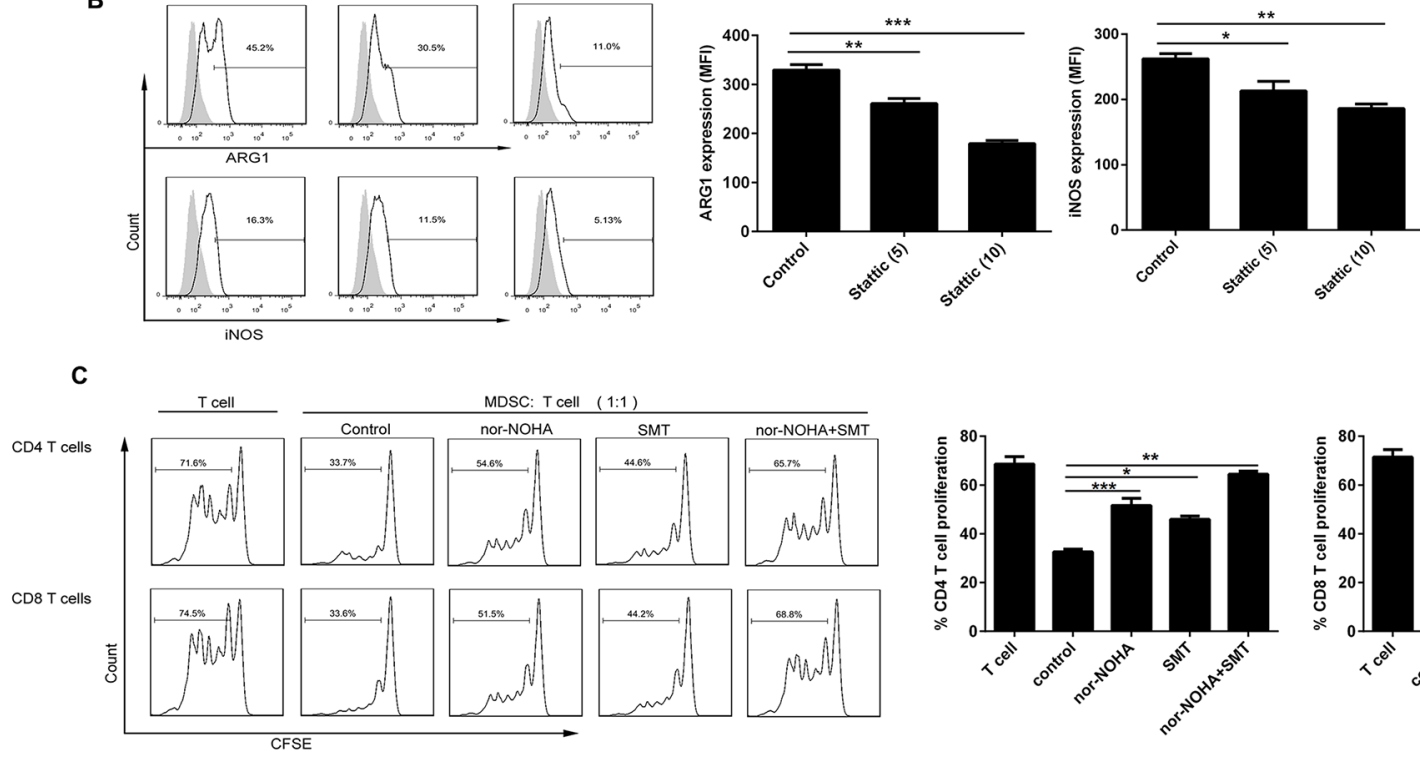

Figure 6: Both ARG1 and iNOS mediated the immunosuppressive activity of AF-induced CD14 ${ }^{+}$HLA-DR $^{-/ l o w}$ MDSC. $^{-}$ PBMC from HD $(n=3)$ were treated with the AF $(50 \% \mathrm{v} / \mathrm{v})$ from OC patients $(n=4)$ in the absence (A) or presence (B) of STAT3 inhibitor stattic for 48 hours and then analyzed for the expression of ARG1, iNOS and S100A8/A9 in CD14 HLA-DR ${ }^{-/ 10 w}$ MDSC by flow cytometry as well as (C) assayed for immune suppressive activity on autologous $\mathrm{CD} 4^{+}$and $\mathrm{CD}^{+} \mathrm{T}$ cell proliferation in the absence or presence of specific inhibitors for ARG1 (nor-NOHA; $20 \mu \mathrm{mol}$ ) and/or iNOS (SMT; $100 \mu \mathrm{mol}$ ). The representative dotplots were shown in left panel and the statistics were shown in right graph. The data are expressed as mean \pm SEM of 4 biological replicates and representative of three independent experiments. ${ }^{*} \mathrm{p}<0.05, * * \mathrm{p}<0.01, * * * \mathrm{p}<0.001$, one-way ANOVA followed by Tukey's multiple comparisons test. 
the endogenous or induced antitumor immune responses considering that specific antibodies against IL-6 or their ligand IL-6R have been marketed, which needs to be tested in future clinical trials $[34,35]$.

We also found that IL-10 is involved in AF-driven CD14 ${ }^{+}$HLA-DR ${ }^{-/ \text {low }}$ MDSC expansion and its level in the ascites is negatively associated with RFS of OC patients, which is concordant with previous studies documenting increased IL-10 level in the sera and ascites from OC patients [36, 37]. The detailed mechanisms for IL-10 involvement of MDSC induction in this setting remain to be investigated though it is reasonably postulated that IL-10 synergistically promoted the expansion of MDSC by triggering STAT3 signal in combination with IL-6 [7, 38]. Notably, though neutralization of IL-6 and IL-10 completely abrogated the expansive effect of AF from OC patients for MDSC, combined recombinant IL- 6 and IL-10 treatment did not induce the expansion of MDSC to the extent that achieved by the AF, indicating IL-6 and IL-10 play an essential but insufficient role and also pointing to a potentially complementary role played by other unappreciated mediators present in the ascites in the recruitment and accumulation of ascitic CD14 ${ }^{+} \mathrm{HLA}_{\mathrm{ADR}}{ }^{-}$ ${ }^{\text {low }}$ MDSC. In fact, previous studies have demonstrated that multiple cytokines such as IL- $1 \beta$, TNF- $\alpha$, VEGF, PEG2 etc. have involved in the accumulation of MDSC and their levels have been iteratively described elevated in the ascites from OC patients [7, 12, 37, 39-42]. Future studies are needed to clarify the independent or combinatorial roles of these cytokines in fostering MDSC generation in the ascites/ tumor from OC patients and their clinical significance.

Previous studies have demonstrated the major role of STAT3 signaling pathway by mastering multiple genes critical for the expansion, differentiation and suppressive function of MDSC $[7,8]$, including ARG1, iNOS, S100A8/A9 etc; accordingly, we found that ascites-driven STAT3 signal concomitantly upregulates the expression of ARG1 and iNOS, two key enzymes for the immune suppressive activity of CD14 ${ }^{+} \mathrm{HLA}-$ $\mathrm{DR}^{-/ \text {low }} \mathrm{MDSC}$ as evidenced by the reversal of MDSC's immunosuppressive activity in the presence of their specific inhibitors. It remains to be investigated whether other downstream STAT3-dependent target genes with the immunosuppressive effects (IDO, COX2, IL-10 etc.) was induced in this setting. As the target genes of STAT3, it is also very possible that ascites-derived IL-6/IL-10 induced their production in MDSC via STAT3 activation consequently constituting a positive feedback loop to perpetuating the expansion of MDSC, which needs more studies to clarify. In term of the key role as a regulator of the immunosuppressive properties of MDSC, STAT3 thus represents a candidate target for therapies aiming to reverse MDSC-mediated immunosuppression considering multiple small molecule drugs targeting STAT3 or JAK kinase have been developed over the past several years [43].
Our study has some limitations. First, the follow-up time for OC patients is relatively short (7-18 months after surgery) with a relatively small cohort which may generate a bias in interpreting the data about correlation analysis of RFS and MDSC level and limit the extrapolation of our findings; keeping a close follow-up of current patients and enrollment of more patients will contribute to address this question in future studies. Second, we did not perform simultaneous measurement of other key immune cell subsets such as T cells or B cells in both compartments; as recent studies showing that preoperative neutrophil-to-lymphocyte ratio can predict survival in OC patients [44, 45], it is very possible that the ratio of MDSC to T cells could more accurately predict the clinical outcome of OC patients, which will be checked in our future investigation.

In conclusion, we found the increased abundance of $\mathrm{CD} 14^{+} \mathrm{HLA}-\mathrm{DR}^{- \text {low }} \mathrm{MDSC}$ in the PB and ascites from OC patients that correlates with their poor prognosis; moreover, we show that ascites-derived IL-6 and IL-10 synergistically drive the expansion of these MDSC via STAT3 activation, thus providing a reasonable explanation for the predominantly elevated level of $\mathrm{CD} 14^{+} \mathrm{HLA}^{-\mathrm{DR}^{-/ l o w}}$ MDSC in the ascites from OC patients and complementing their origin other than CXCL12-CXCR4 mediated recruitment previously described [12]. As it has become clear that human MDSC play an important role in the immunosuppression of advanced cancer, various strategies systemically targeting MDSC have been widely developed via elimination, functional inactivation or maturation of MDSC though their efficacy remains to be improved [8]; with regard to $\mathrm{OC}$, however, the efficacy could be optimized by using local delivery of MDSC-targeting agents such as STAT3 or IL-6 blockers into peritoneum thus enhancing the therapeutic efficacy of other OC modalities, which should be evaluated in future clinical trials.

\section{MATERIALS AND METHODS}

\section{Patients}

PBMC, sera and accompanying ascites were obtained from newly 31 diagnosed OC patients of four histological subtypes (serous, mucinous, endometrioid and mixed) in various stages (I-IV) at General Hospital of Chinese PLA, Beijing, China, from February 2015 to March 2016 and 31 age-matched healthy donors, after obtaining the written informed consent. These patients did not receive any preoperative chemoradiotherapy. The statistical and detailed demographics of those patients were shown in Supplementary Table 1 and 2. All patients underwent a primary surgical debulking procedure for clinical staging. Clinical courses were evaluated by RECIST criteria in patients with measurable disease or profiles of serum CA125 levels in patients without measurable lesions, according to the recommendations by the Gynecologic Cancer InterGroup (GCIG, http://www.gcig.igcs.org=CA-125.html). 


\section{Cell isolation}

PBMC were isolated from the PB of healthy donors and $\mathrm{OC}$ patients by density gradient centrifugation. In brief, blood was collected in EDTA-treated tubes, diluted 1/2 with RPMI 1640 medium, and carefully layered onto a density gradient Ficoll-Hypaque (GE Healthcare). After centrifugation, the band of PBMC was aspirated; $\mathrm{PBMC}$ were washed three times with ice-cold PBS containing 1\% of human serum. Cell viability was checked by trypan blue dye exclusion.

For isolating immune cells from the ascites from OC patients, freshly ascites were collected aseptically and ascites cells were harvested by centrifugation from which immune cells were isolated using density gradient centrifugation as described above.

\section{Flow cytometric analysis}

All monoclonal antibodies used in the study were purchased from Biolegend. For MDSC identification, we used PE-Cy7-anti-HLA-DR, FITC-anti-CD14 APC-antiCD33 and/or APC-anti-CD45 antibodies. For phenotyping MDSC, we first gated MDSCs using anti-HLA-DR/ CD14 antibodies and then costained with PE-anti-CD11b, CD13, CD15, CD39, CD73, CD80, CD83, CD86, CD124 (IL-4R $\alpha$ ), PD-1 (CD279), PD-L1 (CD274), and PD-L2 (CD273). For intracellular cytokine staining, cells were surface stained with anti-CD4/CD8 antibodies followed by permeabilization with the Cytofix/Cytoperm kit (BD Biosciences) and then staining with PE-anti-IL-2 or PE-antiIFN- $\gamma$ antibodies. Isotype-matched antibodies were used as controls. Data acquisition and analysis were performed using the flow cytometer (FC500 MPL, Beckman Coulter) and FlowJo software (Tree Star, Ashland, OR) respectively.

\section{Quantification of cytokines in the sera and ascites}

The levels of IL-1 $\beta$, IL-2, IL-4, IL-5, IL-6, IL-9, IL10, IL-13, IL-17A, IL-22, IFN- $\gamma$ and TNF- $\alpha$ cytokines were determined using the cytometric bead array system (BD eBioscience). Experiments were carried out following the manufacture's instruction manual. In brief, $50 \mu \mathrm{L}$ of each vitreous body sample was incubated for $1 \mathrm{~h}$ with appropriate amounts of detection beads, which were specific for each investigated factor. Afterwards, samples were incubated for $2 \mathrm{~h}$ with detection reagent, which again was specific for each used detection bead. Samples were measured on a FACS Canto II and analyzed by FCAP array software.

\section{MDSC functional assay}

$\mathrm{CD}^{+} 4^{+} \mathrm{HLA}_{-\mathrm{DR}}^{-/ \text {low }} \mathrm{MDSC}$ and CD $14^{+} \mathrm{HLA}^{-D R}{ }^{+}$ control cells in the PB and/or ascites from OC patients or in AF-treated PBMC from HD were purified by using MoFloTM XDP cell sorting system (Beckmam Coulter) with the purity of all isolated cell populations more than 95\% (Supplementargy Figure 1F). Purified MDSC and control cells were cocultured at the varying ratios with autologous PBMC labeled with $2 \mu \mathrm{M}$ CFSE (Molecular Probe) according to the manufacturer's instructions in the presence of soluble anti-CD3 $(2 \mu \mathrm{g} / \mathrm{ml}$; Biolegend $)$ and anti-CD28 $(0.5 \mu \mathrm{g} / \mathrm{ml}$; Biolegend $)$ antibodies. After 72 hours, T-cell proliferation and IFN- $\gamma$ production were assessed by CFSE dilution and intracellular cytokine staining by flow cytometry. In some instances, coculture was performed in the presence of specific inhibitors for ARG1 (nor-NOHA; Calbiochem) at $20 \mu \mathrm{mol}$ and/or iNOS (SMT; Sigma) at $100 \mu \mathrm{mol}$.

\section{MDSC induction by AF}

PBMC from healthy donors were cultured in the presence of varying concentrations $(10,30,50 \% \mathrm{v} / \mathrm{v})$ of AF from OC patients for 24, 48 or 72 hours, and resultant cells were analyzed for the frequency of or ARG1, iNOS, S100A8/A9 (Santa cruz) expression in MDSC by flow cytometry. In some instances, PBMC were cultured with the $\mathrm{AF}$ in the presence of neutralizing antibodies against IL-6 and/or IL-10 (Biolegend) or STAT3 inhibitor stattic (Selleck) with isotype antibody or DMSO as controls. In additional settings, PBMC from healthy donors were treated with recombinant human IL-6 and IL-10 (Peprotech) at indicated concentration with or without STAT3 inhibitor stattic for 48 hours.

\section{Western blotting analysis}

Western blotting was done as we previously described [46] using the following primary antibodies: phosphorylated STAT3 (p-STAT3, Tyr705), total STAT3 and GAPDH from Cell Signaling Technology. HRP-conjugated goat anti-rabbit secondary antibodies (Cell Signaling Technology) were used for enhanced chemiluminescence of western blots.

\section{Statistical analysis}

Statistical analysis was performed on GraphPad Prism 5.0 software (GraphPad Software, United States). Differences between groups were evaluated by twotailed paired or unpaired Student's t test or one-way ANOVA followed by Tukey's multiple comparisons test; correlation between groups was evaluated by Pearson test. RFS was defined as the time period from date of surgery until disease recurrence due to $\mathrm{OC}$ and calculated using the Kaplan-Meier method. Survival differences between groups were assessed using Mantel-Cox log-rank test. P value $<0.05$ was considered statistically significant.

\section{CONFLICTS OF INTEREST}

The authors declare no conflicts of interest. 


\section{ACKNOWLEDGMENTS}

This work was supported by the National Natural Science Foundation of China (No. 81372528 and 81672274) and the National High Technology Research and Development Program ("863" Program) of China (No. 2014AA020704).

\section{REFERENCES}

1. Wei H, Zhao L, Hellstrom I, Hellstrom KE and Guo Y. Dual targeting of CD137 co-stimulatory and PD-1 co-inhibitory molecules for ovarian cancer immunotherapy. Oncoimmunology. 2014; 3:e28248.

2. Yeung TL, Leung CS, Yip KP, Au Yeung CL, Wong ST and Mok SC. Cellular and molecular processes in ovarian cancer metastasis. A Review in the Theme: Cell and Molecular Processes in Cancer Metastasis. Am J Physiol Cell Physiol. 2015; 309:C444-456.

3. Lengyel E. Ovarian cancer development and metastasis. Am J Pathol. 2010; 177:1053-1064.

4. Auer K, Bachmayr-Heyda A, Aust S, Sukhbaatar N, Reiner AT, Grimm C, Horvat R, Zeillinger R and Pils D. Peritoneal tumor spread in serous ovarian cancer-epithelial mesenchymal status and outcome. Oncotarget. 2015; 6:17261-17275.

5. Wertel I, Nowicka A, Rogala E and Kotarski J. Peritoneal immune system in patients with advance epithelial ovarian cancer. Int Rev Immunol. 2011; 30:87-101.

6. Condamine T, Ramachandran I, Youn JI and Gabrilovich DI. Regulation of tumor metastasis by myeloid-derived suppressor cells. Annu Rev Med. 2015; 66:97-110.

7. Gabrilovich DI, Ostrand-Rosenberg S and Bronte V. Coordinated regulation of myeloid cells by tumours. Nat Rev Immunol. 2012; 12:253-268.

8. Marvel D and Gabrilovich DI. Myeloid-derived suppressor cells in the tumor microenvironment: expect the unexpected. J Clin Invest. 2015; 125:3356-3364.

9. Youn JI, Nagaraj S, Collazo M and Gabrilovich DI. Subsets of myeloid-derived suppressor cells in tumor-bearing mice. J Immunol. 2008; 181:5791-5802.

10. Bronte V, Brandau S, Chen SH, Colombo MP, Frey AB, Greten TF, Mandruzzato S, Murray PJ, Ochoa A, Ostrand-Rosenberg S, Rodriguez PC, Sica A, Umansky V, Vonderheide RH and Gabrilovich DI. Recommendations for myeloid-derived suppressor cell nomenclature and characterization standards. Nat Commun. 2016; 7:12150.

11. Montero AJ, Diaz-Montero CM, Kyriakopoulos CE, Bronte $\mathrm{V}$ and Mandruzzato S. Myeloid-derived suppressor cells in cancer patients: a clinical perspective. J Immunother. 2012; 35:107-115.

12. Obermajer N, Muthuswamy R, Odunsi K, Edwards RP and Kalinski P. PGE(2)-induced CXCL12 production and CXCR4 expression controls the accumulation of human
MDSCs in ovarian cancer environment. Cancer Res. 2011; 71:7463-7470.

13. Cui TX, Kryczek I, Zhao L, Zhao E, Kuick R, Roh MH, Vatan L, Szeliga W, Mao Y, Thomas DG, Kotarski J, Tarkowski R, Wicha M, Cho K, Giordano T, Liu R, et al. Myeloid-derived suppressor cells enhance stemness of cancer cells by inducing microRNA101 and suppressing the corepressor CtBP2. Immunity. 2013; 39:611-621.

14. Loercher AE, Nash MA, Kavanagh JJ, Platsoucas CD and Freedman RS. Identification of an IL-10-producing HLADR-negative monocyte subset in the malignant ascites of patients with ovarian carcinoma that inhibits cytokine protein expression and proliferation of autologous T cells. $\mathrm{J}$ Immunol. 1999; 163:6251-6260.

15. Huang A, Zhang B, Wang B, Zhang F, Fan KX and Guo YJ. Increased CD14(+)HLA-DR (-/low) myeloid-derived suppressor cells correlate with extrathoracic metastasis and poor response to chemotherapy in non-small cell lung cancer patients. Cancer Immunol Immunother. 2013; 62:1439-1451.

16. Vasquez-Dunddel D, Pan F, Zeng Q, Gorbounov M, Albesiano E, Fu J, Blosser RL, Tam AJ, Bruno T, Zhang $\mathrm{H}$, Pardoll D and Kim Y. STAT3 regulates arginase-I in myeloid-derived suppressor cells from cancer patients. J Clin Invest. 2013; 123:1580-1589.

17. Chen MF, Kuan FC, Yen TC, Lu MS, Lin PY, Chung YH, Chen WC and Lee KD. IL-6-stimulated CD11b+ CD14+ HLA-DR- myeloid-derived suppressor cells, are associated with progression and poor prognosis in squamous cell carcinoma of the esophagus. Oncotarget. 2014; 5:8716-8728.

18. Poschke I, Mougiakakos D, Hansson J, Masucci $\mathrm{GV}$ and Kiessling R. Immature immunosuppressive CD14+HLA-DR-/low cells in melanoma patients are Stat3hi and overexpress CD80, CD83, and DC-sign. Cancer Res. 2010; 70:4335-4345.

19. Hoechst B, Ormandy LA, Ballmaier M, Lehner F, Kruger C, Manns MP, Greten TF and Korangy F. A new population of myeloid-derived suppressor cells in hepatocellular carcinoma patients induces CD4(+)CD25(+)Foxp3(+) T cells. Gastroenterology. 2008; 135:234-243.

20. Feng PH, Lee KY, Chang YL, Chan YF, Kuo LW, Lin TY, Chung FT, Kuo CS, Yu CT, Lin SM, Wang CH, Chou CL, Huang CD and Kuo HP. CD14(+)S100A9(+) monocytic myeloid-derived suppressor cells and their clinical relevance in non-small cell lung cancer. Am J Respir Crit Care Med. 2012; 186:1025-1036.

21. Chikamatsu K, Sakakura K, Toyoda M, Takahashi K, Yamamoto T and Masuyama K. Immunosuppressive activity of CD14+ HLA-DR- cells in squamous cell carcinoma of the head and neck. Cancer Sci. 2012; 103:976-983.

22. Tian T, Gu X, Zhang B, Liu Y, Yuan C, Shao L, Guo Y and Fan K. Increased circulating CD14(+)HLA-DR-/low myeloid-derived suppressor cells are associated with poor 
prognosis in patients with small-cell lung cancer. Cancer Biomark. 2015; 15:425-432.

23. Vuk-Pavlovic S, Bulur PA, Lin Y, Qin R, Szumlanski CL, Zhao X and Dietz AB. Immunosuppressive CD14+HLADRlow/- monocytes in prostate cancer. Prostate. 2010; 70:443-455.

24. Mandruzzato S, Solito S, Falisi E, Francescato S, ChiarionSileni V, Mocellin S, Zanon A, Rossi CR, Nitti D, Bronte V and Zanovello P. IL4Ralpha+ myeloid-derived suppressor cell expansion in cancer patients. J Immunol. 2009; 182:6562-6568.

25. Young A, Mittal D, Stagg J and Smyth MJ. Targeting cancer-derived adenosine: new therapeutic approaches. Cancer Discov. 2014; 4:879-888.

26. Ryzhov S, Novitskiy SV, Goldstein AE, Biktasova A, Blackburn MR, Biaggioni I, Dikov MM and Feoktistov I. Adenosinergic regulation of the expansion and immunosuppressive activity of $\mathrm{CD} 11 \mathrm{~b}+\mathrm{Gr} 1+$ cells. J Immunol. 2011; 187:6120-6129.

27. Reinartz S, Schumann T, Finkernagel F, Wortmann A, Jansen JM, Meissner W, Krause M, Schworer AM, Wagner U, Muller-Brusselbach S and Muller R. Mixed-polarization phenotype of ascites-associated macrophages in human ovarian carcinoma: correlation of CD163 expression, cytokine levels and early relapse. Int J Cancer. 2014; 134:32-42.

28. Kumar V, Cheng P, Condamine T, Mony S, Languino LR, McCaffrey JC, Hockstein N, Guarino M, Masters G, Penman E, Denstman F, Xu X, Altieri DC, Du H, Yan C and Gabrilovich DI. CD45 Phosphatase Inhibits STAT3 Transcription Factor Activity in Myeloid Cells and Promotes Tumor-Associated Macrophage Differentiation. Immunity. 2016; 44:303-315.

29. Wouters M, Dijkgraaf EM, Kuijjer ML, Jordanova ES, Hollema H, Welters M, van der Hoeven J, Daemen T, Kroep JR, Nijman HW and van der Burg SH. Interleukin-6 receptor and its ligand interleukin-6 are opposite markers for survival and infiltration with mature myeloid cells in ovarian cancer. Oncoimmunology. 2014; 3:e962397.

30. Kryczek I, Grybos M, Karabon L, Klimczak A and Lange A. IL-6 production in ovarian carcinoma is associated with histiotype and biological characteristics of the tumour and influences local immunity. Br J Cancer. 2000; 82:621-628.

31. Dijkgraaf EM, Welters MJ, Nortier JW, van der Burg SH and Kroep JR. Interleukin-6/interleukin-6 receptor pathway as a new therapy target in epithelial ovarian cancer. Curr Pharm Des. 2012; 18:3816-3827.

32. Coward J, Kulbe H, Chakravarty P, Leader D, Vassileva V, Leinster DA, Thompson R, Schioppa T, Nemeth J, Vermeulen J, Singh N, Avril N, Cummings J, Rexhepaj E, Jirstrom K, Gallagher WM, et al. Interleukin-6 as a therapeutic target in human ovarian cancer. Clin Cancer Res. 2011; 17:6083-6096.

33. Maccio A and Madeddu C. The role of interleukin-6 in the evolution of ovarian cancer: clinical and prognostic implications--a review. J Mol Med (Berl). 2013; 91:1355-1368.

34. Sumida K, Wakita D, Narita Y, Masuko K, Terada S, Watanabe K, Satoh T, Kitamura H and Nishimura T. Anti-IL-6 receptor $\mathrm{mAb}$ eliminates myeloid-derived suppressor cells and inhibits tumor growth by enhancing T-cell responses. Eur J Immunol. 2012; 42:2060-2072.

35. Dijkgraaf EM, Santegoets SJ, Reyners AK, Goedemans R, Wouters MC, Kenter GG, van Erkel AR, van Poelgeest MI, Nijman HW, van der Hoeven JJ, Welters MJ, van der Burg SH and Kroep JR. A phase I trial combining carboplatin/ doxorubicin with tocilizumab, an anti-IL-6R monoclonal antibody, and interferon-alpha $2 \mathrm{~b}$ in patients with recurrent epithelial ovarian cancer. Ann Oncol. 2015; 26:2141-2149.

36. Nowak M, Glowacka E, Szpakowski M, Szyllo K, Malinowski A, Kulig A, Tchorzewski H and Wilczynski J. Proinflammatory and immunosuppressive serum, ascites and cyst fluid cytokines in patients with early and advanced ovarian cancer and benign ovarian tumors. Neuro Endocrinol Lett. 2010; 31:375-383.

37. Lane D, Matte I, Garde-Granger P, Laplante C, Carignan A, Rancourt $\mathrm{C}$ and Piche A. Inflammation-regulating factors in ascites as predictive biomarkers of drug resistance and progression-free survival in serous epithelial ovarian cancers. BMC Cancer. 2015; 15:492.

38. Ouyang W, Rutz S, Crellin NK, Valdez PA and Hymowitz SG. Regulation and functions of the IL-10 family of cytokines in inflammation and disease. Annu Rev Immunol. 2011; 29:71-109.

39. Lechner MG, Liebertz DJ and Epstein AL. Characterization of cytokine-induced myeloid-derived suppressor cells from normal human peripheral blood mononuclear cells. J Immunol. 2010; 185:2273-2284.

40. Kolomeyevskaya N, Eng KH, Khan AN, Grzankowski KS, Singel KL, Moysich K and Segal BH. Cytokine profiling of ascites at primary surgery identifies an interaction of tumor necrosis factor-alpha and interleukin-6 in predicting reduced progression-free survival in epithelial ovarian cancer. Gynecol Oncol. 2015; 138:352-357.

41. Zhan N, Dong WG and Wang J. The clinical significance of vascular endothelial growth factor in malignant ascites. Tumour Biol. 2016; 37:3719-3725.

42. Horikawa N, Abiko K, Matsumura N, Hamanishi J, Baba T, Yamaguchi K, Yoshioka Y, Koshiyama M and Konishi I. Expression of Vascular Endothelial Growth Factor in Ovarian Cancer Inhibits Tumor Immunity through the Accumulation of Myeloid-Derived Suppressor Cells. Clin Cancer Res. 2017; 23:587-599.

43. Yu H, Lee H, Herrmann A, Buettner R and Jove R. Revisiting STAT3 signalling in cancer: new and unexpected biological functions. Nat Rev Cancer. 2014; 14:736-746.

44. Li Z, Hong N, Robertson $\mathrm{M}$, Wang $\mathrm{C}$ and Jiang $\mathrm{G}$. Preoperative red cell distribution width and neutrophil-tolymphocyte ratio predict survival in patients with epithelial ovarian cancer. Sci Rep. 2017; 7:43001. 
45. Feng Z, Wen H, Bi R, Ju X, Chen X, Yang W and Wu $X$. Preoperative Neutrophil-to-Lymphocyte Ratio as a Predictive and Prognostic Factor for High-Grade Serous Ovarian Cancer. PLoS One. 2016; 11:e0156101.
46. Li G, Zhao L, Li W, Fan K, Qian W, Hou S, Wang H, Dai J, Wei $\mathrm{H}$ and Guo Y. Feedback activation of STAT3 mediates trastuzumab resistance via upregulation of MUC1 and MUC4 expression. Oncotarget. 2014; 5:8317-8329. 